OPEN ACCESS

Edited by:

Wilna Vosloo,

Commonwealth Scientific and Industrial Research Organisation

(CSIRO), Australia

Reviewed by:

Nagendrakumar Singanallur

Balasubramanian

Australian Animal Health Laboratory

(CSIRO), Australia

Sabrina Galdo Novo,

University of Buenos Aires, Argentina

${ }^{*}$ Correspondence:

Ashley R. Gray

ashley.gray@pirbright.ac.uk

Specialty section:

This article was submitted to Veterinary Infectious Diseases,

a section of the journal

Frontiers in Veterinary Science

Received: 14 April 2020

Accepted: 12 June 2020

Published: 28 July 2020

Citation:

Gray AR, Wood BA, Henry E,

Azhar M, King DP and Mioulet V (2020) Evaluation of Cell Lines for the Isolation of Foot-and-Mouth Disease

Virus and Other Viruses Causing Vesicular Disease.

Front. Vet. Sci. 7:426

doi: 10.3389/fvets.2020.00426

\section{Evaluation of Cell Lines for the Isolation of Foot-and-Mouth Disease Virus and Other Viruses Causing Vesicular Disease}

\author{
Ashley R. Gray*, Britta A. Wood, Elisabeth Henry, Mehreen Azhar, Donald P. King and \\ Valérie Mioulet
}

Vesicular Disease Reference Laboratory, The Pirbright Institute, Surrey, United Kingdom

The most sensitive cell culture system for the isolation of foot-and-mouth disease virus (FMDV) is primary bovine thyroid (BTY) cells. However, BTY cells are seldom used because of the challenges associated with sourcing thyroids from FMDV-negative calves (particularly in FMD endemic countries), and the costs and time required to regularly prepare batches of cells. Two continuous cell lines, a fetal goat tongue cell line (ZZ-R 127) and a fetal porcine kidney cell line ( $\left.\mathrm{LFBK}-\alpha_{\vee} \beta_{6}\right)$, have been shown to be highly sensitive to FMDV. Here, we assessed the sensitivity of ZZ-R 127 and LFBK- $\alpha \vee \beta_{6}$ cells relative to primary BTY cells by titrating a range of FMDV original samples and isolates. Both the ZZ-R 127 and LFBK- $\alpha \vee \beta_{6}$ cells were susceptible to FMDV for >100 passages, and there were no significant differences in sensitivity relative to primary BTY cells. Notably, the LFBK- $\alpha_{v} \beta_{6}$ cell line was highly sensitive to the O/CATHAY porcine-adapted FMDV strain. These results support the use of ZZ-R 127 and LFBK- $\alpha \vee \beta_{6}$ as sensitive alternatives to BTY cells for the isolation of FMDV, and highlight the use of LFBK- $\alpha_{v} \beta_{6}$ cells as an additional tool for the isolation of porcinophilic viruses.

Keywords: foot-and-mouth disease virus, virus isolation, cell line, diagnosis, vesicular viruses

\section{INTRODUCTION}

Foot-and-mouth disease (FMD) is a highly contagious disease of cloven-hoofed animals, which results in widespread economic burden (1). The major cause of global spread is the transboundary movement of animals, and as such, animal trade is restricted in countries where the disease is present (2). Foot-and-mouth disease virus (FMDV; family Picornaviridae, genus Aphthovirus) is the causative agent, and there are seven different serotypes [O, A, C, Asia 1, Southern African Territories (SAT) 1, SAT 2, and SAT 3; (3)], with many different topotypes within each serotype (4).

Control of FMD is underpinned by rapid and accurate diagnosis. Virus isolation using susceptible cell cultures is beneficial for the amplification of virus for downstream diagnostic tests, including FMD serotyping by antigen enzyme linked immunosorbent assay (ELISA) (5) and sequencing of the VP1 region of the genome (6). Cell cultures are also required to produce FMDV vaccines, which are currently based on inactivated whole virus preparations (7). Control of FMD through vaccination is complicated by limited cross serotype/topotype immunity and therefore, vaccine matching field isolates using susceptible cell lines is an essential tool for appropriate vaccine selection (7). 
Primary bovine thyroid (BTY) cell cultures are the most sensitive system for the isolation of FMDV (8), but their use is not widespread because of the difficulties obtaining tissue, the time and expense required to prepare the cells, and the fact that the cells have a relatively short life span. Immortalized cell lines, such as baby hamster kidney fibroblasts (BHK-21) and pig kidney (IB-RS-2) cells, provide a stable source of susceptible cultures, but are generally less sensitive to FMDV (8). Nonetheless, porcine cells (e.g., IB-RS-2) are commonly required for the isolation of FMDV strains that have naturally adapted to infect pigs (9), such as the serotype O/CATHAY topotype, which do not replicate in BTY cells. For diagnostic laboratories, it is also important that cell culture systems are able to support the propagation of viruses that cause clinical disease that are indistinguishable from FMDV, such as swine vesicular disease virus (SVDV), vesicular exanthema of swine (VESV), vesicular stomatitis virus (VSV), and Seneca Valley virus (SVV).

Fetal porcine kidney (LFBK- $\left.\alpha_{V} \beta_{6}\right)$ cells, which have been engineered to express bovine $\alpha_{V} \beta_{6}$ integrin, a principal cellular receptor of FMDV, and fetal goat tongue cells (ZZ-R 127) are two continuous cell lines that are highly sensitive to FMDV $(10-12)$. A number of studies have utilized the LFBK- $\alpha_{V} \beta_{6}$ and ZZ-R 127 cell lines for the isolation of FMDV from different clinical samples (13-20). In previous studies, the ZZ-R 127 cell line provided similar sensitivity to FMDV as primary BTY cells (10) and LFBK- $\alpha_{V} \beta_{6}$ cells (21), however to our knowledge the LFBK- $\alpha_{V} \beta_{6}$ cell line has not been compared to BTY cells. The World Reference Laboratory for FMD (WRLFMD; The Pirbright Institute, UK) currently utilizes BTY and IB-RS-2 cells for the diagnosis of FMDV. In this study, the diagnostic capabilities of ZZ-R 127 and LFBK- $\alpha_{V} \beta_{6}$ cells lines were evaluated using epithelium suspensions from a range of FMDV serotypes/subtypes, as well as the effects of different sample matrices commonly used for the isolation of FMDV. Through comparative titrations, we assessed the longevity of sensitivity of ZZ-R 127 and LFBK- $\alpha_{V} \beta_{6}$ cells lines to FMDV isolates alongside BTY and IB-RS- 2 cells. Finally, the ability of ZZ-R 127 and LFBK$\alpha_{V} \beta_{6}$ cells lines to propagate representative isolates of VESV, VSV, and SVV was also determined.

\section{MATERIALS AND METHODS}

All experiments were conducted at The Pirbright Institute in high-containment laboratories that meet the Minimum Biorisk Management Standards for Laboratories Working with Footand-Mouth Disease Virus of the European Commission for the Control of Foot-and-Mouth Disease (22).

\section{Cells}

BTY cells were prepared weekly incorporating variations from the method previously described in Snowdon (23). Briefly, bovine calf thyroids were obtained from an abattoir, dissociated using dispase II (Gibco), and cultured using Eagle's Glasgow minimal essential medium (GMEM; Sigma) supplemented with $12 \mathrm{~mL} / \mathrm{L}$ field antibiotics $\left(0.002 \mathrm{mg} / \mathrm{mL}\right.$ amphotericin $\mathrm{B}, 10^{-4} \mathrm{MU} / \mathrm{mL}$ penicillin, $49 \mu \mathrm{g} / \mathrm{mL}$ neomycin, $98 \mathrm{U} / \mathrm{mL}$ polymyxin $\mathrm{B}$, sterile water), $10 \mathrm{~mL} / \mathrm{L} \mathrm{L}$-glutamine (Sigma), and $10 \%$ adult bovine serum (ABS; Sigma). The BTY cells were counted using a FuchsRosenthal counting chamber and the concentration normalized to a seeding density of $6 \times 10^{5}$ cells $/ \mathrm{mL}$. The BTY cells were cultured in Nunc ${ }^{\mathrm{TM}}$ flat-sided cell culture tubes $\left(5.5 \mathrm{~cm}^{2}\right.$; Thermo Fisher Scientific) using $2 \mathrm{~mL}$ of cell suspension and incubated stationary at $37^{\circ} \mathrm{C}$. After $96 \mathrm{~h}$, the media was discarded from each tube and replaced with GMEM (Sigma) supplemented field antibiotics and L-glutamine as above and between 2 and 10\% ABS (Sigma). The percentage of ABS used was dependent on the average level of confluency observed in 10 tubes after $96 \mathrm{~h}$ (e.g., $<40 \%$ confluence $-10 \%$ ABS, $40-60 \%$ confluence - $7 \%$ ABS, 60 $90 \%$ confluence $-5 \%$ ABS, $>90 \%$ confluence $-2 \%$ ABS). After the media change, the cell culture tubes were incubated with rotation at $37^{\circ} \mathrm{C}$ until use.

IB-RS- 2 cells were maintained in T-175 cell culture flasks using GMEM (Gibco) supplemented with 10\% adult bovine serum (Sigma). The seed stocks were passaged to reach $90-100 \%$ confluency in 72 to $96 \mathrm{~h}$. The IB-RS-2 cells were prepared in Nunc ${ }^{\mathrm{TM}}$ cell culture tubes using $2 \mathrm{~mL}$ of cell suspension at a concentration between 0.5 and $6 \times 10^{5}$ cells $/ \mathrm{mL}$ to reach 90 $100 \%$ confluency between 24 and $96 \mathrm{~h}$. Seed flasks and cell culture tubes were incubated stationary at $37^{\circ} \mathrm{C}$ until use.

ZZ-R 127 cells, supplied by the Friedrich-Loeffler-Institute (Greifswald-Insel Riems, Germany), were maintained in T-175 cell culture flasks using Dulbecco's modified Eagle medium: F12 (DMEM; Lonza) supplemented with $10 \%$ fetal bovine serum (Gibco). The seed stocks were passaged to reach $90-100 \%$ confluency in $96 \mathrm{~h}$. The ZZ-R 127 cells were cultured in Nunc ${ }^{\mathrm{TM}}$ cell culture tubes using $2 \mathrm{~mL}$ of cell suspension at a concentration of $0.65 \times 10^{5}$ cells $/ \mathrm{mL}$ to reach $90-100 \%$ confluency in $96 \mathrm{~h}$. Seed flasks and cell culture tubes were incubated stationary at $37^{\circ} \mathrm{C}$ until use.

LFBK- $\alpha_{V} \beta_{6}$ cells $(11,12)$, supplied by the Animal and Plant Health Inspection Service, Diagnostic Service Section at the Plum Island Animal Disease Center (Long Island, NY, USA), were maintained in T-175 cell culture flasks using DMEM (Gibco) supplemented with $10 \%$ fetal bovine serum (Gibco). The seed stocks were passaged to reach $90-100 \%$ confluency in $72 \mathrm{~h}$. The LFBK- $\alpha_{V} \beta_{6}$ cells were cultured in Nunc ${ }^{\mathrm{TM}}$ cell culture tubes using $2 \mathrm{~mL}$ of cell suspension at a concentration of 2 $\times 10^{5}$ cells $/ \mathrm{mL}$ to reach $90-100 \%$ confluency in $72 \mathrm{~h}$. Seed flasks and cell culture tubes were incubated stationary at $37^{\circ} \mathrm{C}$ until use.

Preparation of primary cell cultures and passaging of continuous cell lines were performed inside a class 2 microbiological safety cabinet. Biocontainment procedures were required for the maintenance of IB-RS-2 cells and LFBK$\alpha_{V} \beta_{6}$ cells, which are persistently infected with classical swine fever (CSF) virus (24) and a non-cytopathic bovine viral diarrhea virus (BVDV; Rodriguez LL, personal communication, 2019), respectively. All virus isolations and titrations were performed using monolayers of $90-100 \%$ confluency cultured in $\mathrm{Nunc}^{\mathrm{TM}}$ cell culture tubes. All cell culture tubes received minimal essential media (MEM; Gibco) supplemented with $6 \mathrm{~mL} / \mathrm{L}$ field antibiotics and 2\% fetal bovine serum (Gibco) to sustain cell cultures after the addition of virus and negative matrices. 


\section{Virus Stocks}

In line with the OIE manual (25), FMDV and SVDV original suspensions were prepared by homogenizing vesicular epithelium as a $10 \%$ solution in M25 buffer $(35 \mathrm{mM}$ disodium hydrogen phosphate, $5.7 \mathrm{mM}$ potassium dihydrogen phosphate, sterile water). The tissue was homogenized with sterile sand (Sigma) using a sterilized pestle and mortar. The suspension was clarified by centrifugation at $3,000 \mathrm{~g}$ for $10 \mathrm{~min}$ at $4^{\circ} \mathrm{C}$.

Epithelial suspensions tested in the diagnostic sensitivity experiments were either used immediately after preparation or aliquoted and stored at $-80^{\circ} \mathrm{C}$. The suspensions of FMDV/A/IRN/24/2012, FMDV/O/KUW/4/2016 and SVDV/UKG/77/80 prepared for the longevity of sensitivity experiments were mixed 1:1 with glycerol (VWR chemicals) for long term storage at $-20^{\circ} \mathrm{C}$. SVV, VESV, and VSV New Jersey isolates of known high viral titers were selected from the WRLFMD virus collection.

\section{Virus Titrations}

Virus titrations were performed in parallel to compare the relative sensitivity of the cell lines to FMDV and SVDV. Virus stocks were serially diluted 10 -fold in M25 buffer. Cells $(n=4$ or 5 tubes per cell line) were washed with $2 \mathrm{~mL}$ sterile phosphate buffer saline (PBS; Severn Biotech) before adding $2 \mathrm{~mL}$ of MEM (Gibco). The cell tubes were then inoculated with $0.2 \mathrm{~mL}$ of the appropriate virus dilution and incubated with rotation at $37^{\circ} \mathrm{C}$ for $72 \mathrm{~h}$, after which the cells were visually examined under a microscope for cytopathic effect (CPE). For each cell line, viral titers were calculated using the Spearman-Karber method and expressed as $\log _{10} \mathrm{TCID}_{50} / \mathrm{mL}$, where a higher viral titer in a cell line correlated to a lower limit of detection and greater analytical sensitivity.

A/IRN/24/2012 and O/KUW/4/2016 glycerinated epithelium suspensions were initially titrated with BTY cells to establish baseline titers (6.6 and $7.8 \log _{10} \mathrm{TCID}_{50} / \mathrm{mL}$, respectively). The continued sensitivity of ZZ-R 127 and LFBK- $\alpha_{V} \beta_{6}$ to FMDV was assessed by titrating $\mathrm{A} / \mathrm{IRN} / 24 / 2012$ or $\mathrm{O} / \mathrm{KUW} / 4 / 2016$ during continued passaging of the cell lines; all titrations were performed in parallel with BTY and IB-RS-2 cells. A/IRN/24/2012 was used for 9 months (16th May 2017 to 6th February 2018) until viral titers began to decrease across all cell lines, possibly due to sample degradation, and was replaced with $\mathrm{O} / \mathrm{KUW} / 4 / 2016$ that was used for 10 months (12th February 2018 to 18th December 2018).

SVDV/UKG/77/80 glycerinated epithelium suspension was initially titrated with IB-RS-2 cells to establish a baseline titer (3.8 $\log _{10} \mathrm{TCID}_{50} / \mathrm{mL}$ ). The sensitivity of the LFBK- $\alpha_{V} \beta_{6}$ cell line to SVDV was assessed over time by titrating UKG/77/80 during continued passaging of the cell line; all titrations were performed in parallel with IB-RS-2 cells. The ZZ-R 127 cell line was not included in these experiments because SVDV does not propagate in this cell line (10).

\section{FMDV Diagnostic Sensitivity}

Forty epithelium suspensions (Table 1), representing five serotypes and thirteen topotypes of FMDV (O $n=20, \mathrm{~A} n=8$, SAT $1 n=4$, SAT $2 n=3$, and Asia $1 n=5$ ), were either retrieved from $-80^{\circ} \mathrm{C}$ storage or prepared from epithelial tissue. Titrations
TABLE 1 | Number of epithelium suspensions tested by serotype and lineage.

\begin{tabular}{|c|c|c|c|c|}
\hline Serotype & Topotype & Lineage & Sub-lineage & $\begin{array}{l}\text { No of } \\
\text { isolates }\end{array}$ \\
\hline \multirow[t]{11}{*}{$\mathrm{O}$} & CATHAY & - & - & 8 \\
\hline & $\begin{array}{c}\text { SOUTH EAST } \\
\text { ASIA }\end{array}$ & Mya-98 & - & 1 \\
\hline & $\begin{array}{c}\text { MIDDLE EAST } \\
\text { SOUTH ASIA }\end{array}$ & Ind-2001 & $d$ & 2 \\
\hline & & & e & 1 \\
\hline & & PanAsia & - & 1 \\
\hline & & PanAsia2 & ANT-10 & 1 \\
\hline & & & BAL-09 & 2 \\
\hline & & & QOM-15 & 1 \\
\hline & WEST AFRICA & - & - & 1 \\
\hline & EAST AFRICA 2 & - & - & 1 \\
\hline & EAST AFRICA 3 & - & - & 1 \\
\hline \multirow[t]{5}{*}{ A } & ASIA & Iran-05 & FAR-11 & 2 \\
\hline & & & SIS-13 & 2 \\
\hline & & & SIS-10 & 1 \\
\hline & & G-VII & - & 2 \\
\hline & AFRICA & G-IV & - & 1 \\
\hline \multirow[t]{3}{*}{ SAT 1} & III & - & - & 1 \\
\hline & III (WZ) & - & - & 2 \\
\hline & $x$ & - & - & 1 \\
\hline \multirow[t]{2}{*}{ SAT 2} & VII & Alx-12 & - & 2 \\
\hline & & Lib-12 & - & 1 \\
\hline \multirow[t]{3}{*}{ ASIA 1} & ASIA & Sindh-08 & - & 3 \\
\hline & & - & - & 2 \\
\hline & \multicolumn{2}{|c|}{ Total } & & 40 \\
\hline
\end{tabular}

were performed with BTY, ZZ-R 127, and LFBK- $\alpha_{V} \beta_{6}$ cells for all samples, except for the O/CATHAY topotype. O/CATHAY is a porcine adapted strain and does not replicate in BTY cells. The O/CATHAY samples were titrated using IB-RS-2, ZZ-R 127, and LFBK- $\alpha_{V} \beta_{6}$ cells.

Twenty-six diagnostic porcine epithelium suspensions originating from Hong Kong were inoculated onto BTY, IB-RS2 , and LFBK- $\alpha_{V} \beta_{6}$ cells. Each cell tube $(n=4$ or 5 tubes per cell line) was washed with $2 \mathrm{~mL}$ sterile PBS and then inoculated with $0.2 \mathrm{~mL}$ of sample. The tubes were incubated stationary at $37^{\circ} \mathrm{C}$ for $30 \mathrm{~min}$ and after incubation, each tube received $2 \mathrm{~mL}$ MEM. Cell culture tubes were incubated at $37^{\circ} \mathrm{C}$ with rotation and examined microscopically for CPE every $24 \mathrm{~h}$ up to a maximum of $96 \mathrm{~h}$. All isolated samples were then characterized by antigen ELISA (5) and VP1 sequencing.

\section{Matrix Cytotoxicity}

To determine whether sample matrices have an effect on cell monolayers, undiluted bovine serum, milk, probang, and whole blood were inoculated onto BTY, IB-RS-2, ZZ-R 127, and LFBK$\alpha_{V} \beta_{6}$ cells, and a $10 \%$ fecal suspension (SVDV sample type) was inoculated on IB-RS- 2 and LFBK- $\alpha_{V} \beta_{6}$ cells. Each cell tube ( $n$ $=4$ per cell line) was washed with $2 \mathrm{~mL}$ sterile PBS and then inoculated with $0.2 \mathrm{~mL}$ of the matrix. The tubes were incubated 


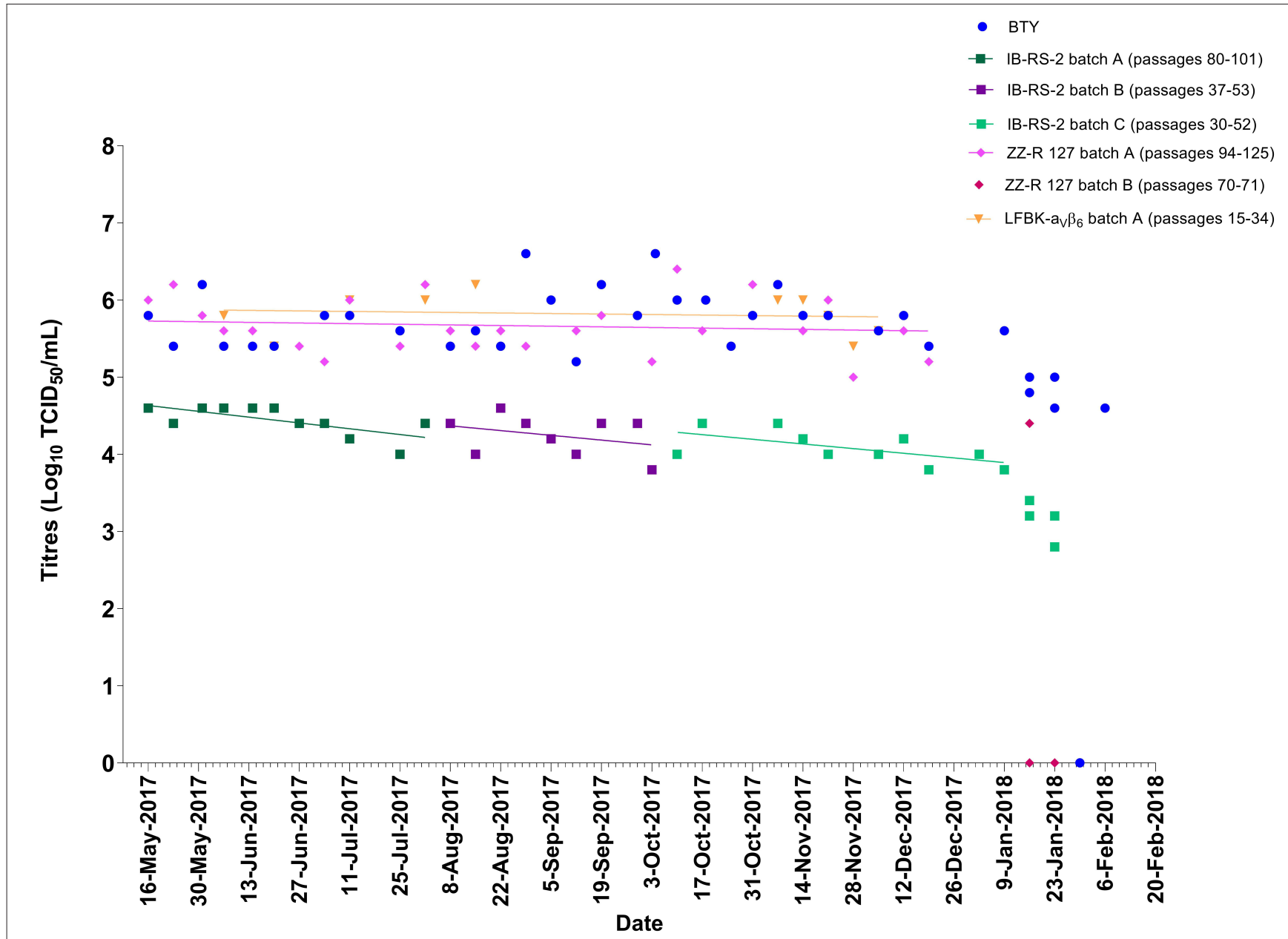

FIGURE 1 | Titers of FMDV A/IRN/24/2012 epithelium suspension tested on BTY, IB-RS-2, ZZ-R 127, and LFBK- $\alpha_{V} \beta_{6}$ cells. The lines represent the trend of titers over time. No trendline is present for BTY cells as these are independent, weekly batches.

stationary at $37^{\circ} \mathrm{C}$ for $30 \mathrm{~min}$. After incubation, the monolayers were washed at least 3 times with $2 \mathrm{~mL}$ sterile PBS before adding $2 \mathrm{~mL}$ MEM to each tube. Cell culture tubes were incubated at $37^{\circ} \mathrm{C}$ with rotation for $72 \mathrm{~h}$, and then examined microscopically for cytotoxicity.

\section{SVV, VESV, and VSV}

BTY, IB-RS-2, ZZ-R 127, and LFBK- $\alpha_{V} \beta_{6}$ cells ( $n=3$ tubes per cell line) were assessed for their ability to propagate SVV, VESV, and VSV. Cell culture tubes were washed with $2 \mathrm{~mL}$ sterile PBS and each tube received $2 \mathrm{~mL}$ MEM. Tubes were inoculated with $0.2 \mathrm{~mL}$ of SVV, VESV, or VSV, and then incubated at $37^{\circ} \mathrm{C}$ with rotation for $72 \mathrm{~h}$. After $72 \mathrm{~h}$, the cell monolayers were examined microscopically for CPE.

\section{Statistical Analysis}

Average viral titers for FMDV/A/IRN/24/2012 and FMDV/O/KUW/4/2016 amongst BTY, IB-RS-2, ZZ-R 127, and LFBK- $\alpha_{V} \beta_{6}$ cells were compared using Kruskal-Wallis and post-hoc Dunn's multiple comparisons tests. Average viral titers for SVDV/UKG/77/80 between IB-RS-2 and LFBK- $\alpha_{V} \beta_{6}$ were compared using the Mann-Whitney test. Where epithelial suspensions were tested amongst cell lines and provided a single data point, the differences in sensitivity to FMDV for ZZ-R 127 and LFBK- $\alpha_{V} \beta_{6}$ were compared to BTY cells independently, using paired $t$-tests. Statistical analysis was not performed on the O/CATHAY sensitivity data due to the low number of isolates detected. Statistical analyses were performed on log transformed titer values using Graphpad Prism 8.1.2. $P<0.05$ were considered significant.

\section{RESULTS}

Longevity of Sensitivity to FMDV and SVDV

Over a 19-month period, weekly titrations were performed on BTY, IB-RS-2, ZZ-R 127, and/or LFBK- $\alpha_{V} \beta_{6}$ cells using FMDV A/IRN/24/2012 (Figure 1) or O/KUW/4/2016 (Figure 2) epithelium suspensions; not all cell types were available each 


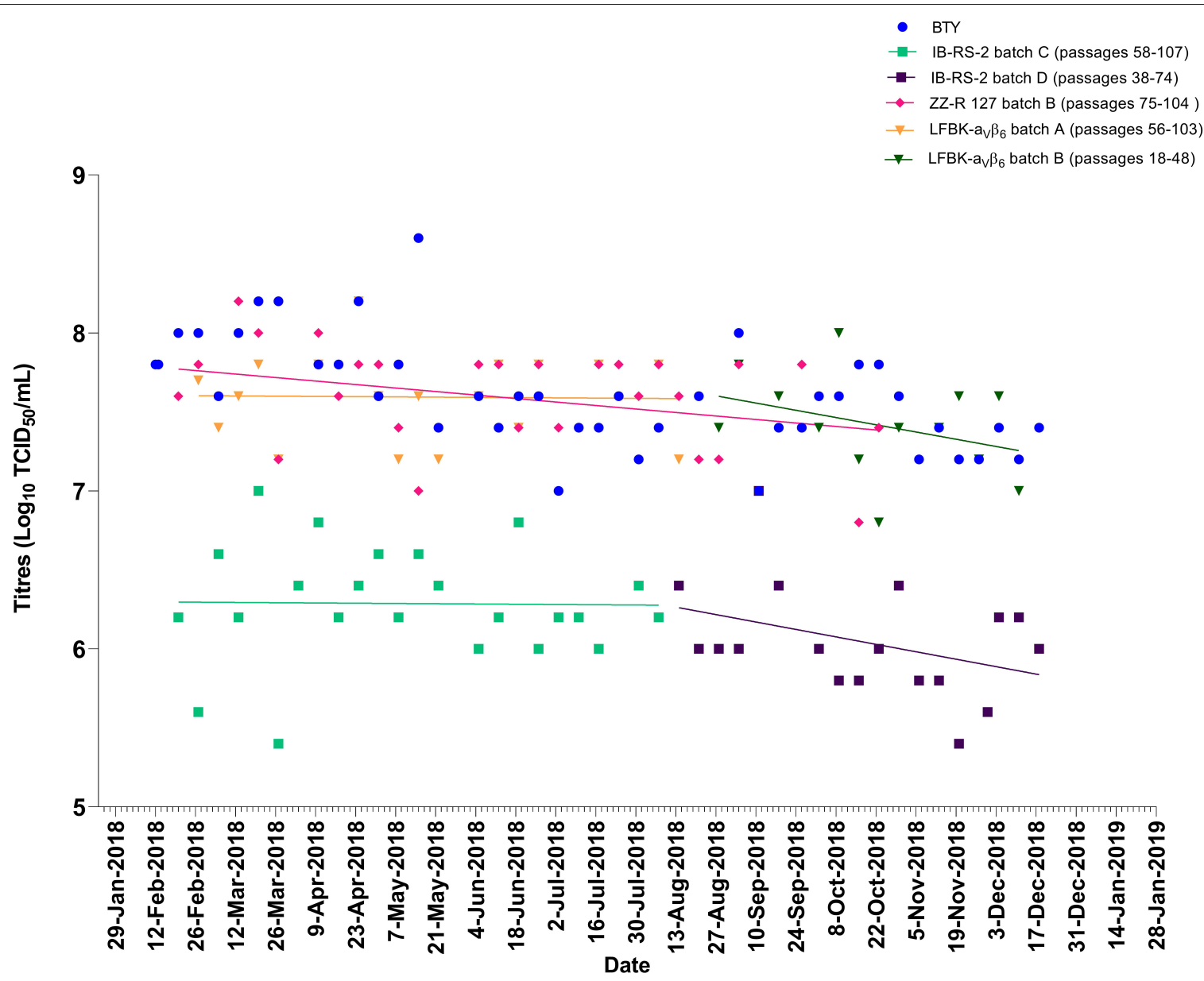

FIGURE 2 | Titers of FMDV O/KUW/4/2016 epithelium suspension tested on BTY, IB-RS-2, ZZ-R 127, and LFBK- $\alpha \vee \beta_{6}$. The lines represent the trend of titers over time. No trendline is present for BTY cells as these are independent, weekly batches.

week, resulting in minor gaps in testing. The viral titers obtained from the weekly batches of BTY cells were within $\pm 1 \log _{10}$. The longevity of sensitivity for IB-RS-2 cells was inconsistent between batches (range 9-35 weeks), and in each case, the cells gradually lost their sensitivity over time, as evident by the decreasing titers (Figure 1). Once a batch of IB-RS-2 cells lost sensitivity, a new batch was revived for testing. The LFBK- $\alpha_{V} \beta_{6}$ and ZZ-R 127 cell lines remained sensitive to FMDV for $>100$ passages, although the LFBK- $\alpha_{V} \beta_{6}$ cells underwent senescence at passage 105 and the batch of cells were replaced. The two batches of ZZ-R 127 cells were replaced (after 33 and 43 weeks) before a noticeable decline in sensitivity to FMDV could be observed.

The average viral titers of epithelium suspensions FMDV/A/IRN/24/2012 (mean \pm standard deviation; BTY; $5.9 \pm 0.3$, ZZ-R 127; $5.8 \pm 0.4$, LFBK- $\alpha_{V} \beta_{6} ; 5.9 \pm 0.3$ and IBRS-2; $4.3 \pm 0.3 \log _{10} \mathrm{TCID}_{50} / \mathrm{mL}$ ) and FMDV/O/KUW/4/2016 (BTY; $7.9 \pm 0.3$, ZZ-R 127; $7.7 \pm 0.3$, LFBK- $\alpha_{V} \beta_{6} ; 7.7 \pm 0.3$ and IB-RS-2; $6.4 \pm 0.4 \log _{10} \mathrm{TCID}_{50} / \mathrm{mL}$ ) were significantly different by cell type $(p<0.001)$. For both FMDV A/IRN/24/2012 and $\mathrm{O} / \mathrm{KUW} / 4 / 2016$, the sensitivity of ZZ-R 127 and LFBK- $\alpha_{V} \beta_{6}$ cells were comparable to BTY cells; however, the sensitivity of the IB-RS-2 cells was significantly lower than BTY, ZZ-R 127 and LFBK- $\alpha_{V} \beta_{6}$ cells $(p<0.0001)$.

Over an 8-month period, weekly titrations were performed on IB-RS- 2 and/or LFBK- $\alpha_{V} \beta_{6}$ cells using SVD/UKG/77/80 (Figure 3). IB-RS-2 and LFBK- $\alpha_{V} \beta_{6}$ cells were not available each week, hence the minor gaps (maximum of 4 weeks) in testing. IBRS- 2 and LFBK- $\alpha_{V} \beta_{6}$ cells remained sensitive to SVDV for $>100$ passages. The LFBK $-\alpha_{V} \beta_{6}$ cells lost sensitivity to SVDV at passage 104 , as indicated by the lack of viral titer (Figure 3). The LFBK$\alpha_{V} \beta_{6}$ trend lines indicate that titers decreased overtime similar to the IB-RS-2 cell line. The average titer for the SVDV/UKG/77/80 epithelium suspension was significantly higher in the LFBK- $\alpha_{V} \beta_{6}$ than IB-RS-2 cells $\left(p<0.001 ; 5.2 \pm 1.2\right.$ and $4.5 \pm 0.5 \log _{10}$ $\mathrm{TCID}_{50} / \mathrm{mL}$, respectively),

\section{Detection of FMDV in Diagnostic Epithelium Suspensions}

Thirty-two epithelium suspensions were titrated using BTY, ZZ-R 127, and LFBK- $\alpha_{V} \beta_{6}$ cells and the limit of detection 


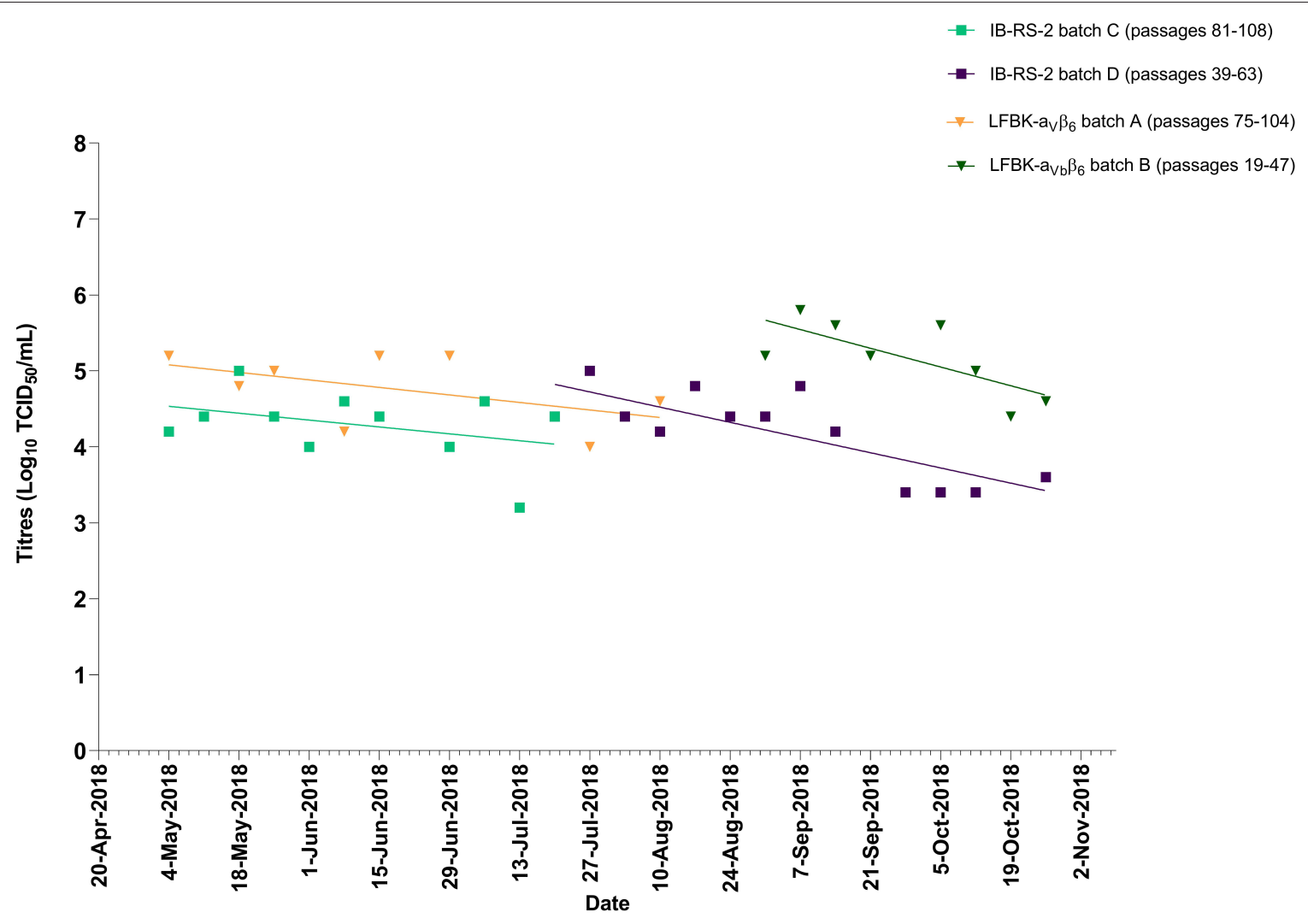

FIGURE 3 | Titers of SVDV/UKG/77/80 epithelium suspension tested on IB-RS-2 and LFBK- $\alpha_{V} \beta_{6}$. The lines represent the trend of titers over time.

compared by calculating the relative viral titer generated in these different cell systems. In the majority of samples tested (29 of 32), the analytical limit of detection for the ZZ-R 127 and LFBK- $\alpha_{V} \beta_{6}$ was comparable to that of the primary BTY cells (Figures 4, 5). Overall, there was no significant difference in analytical sensitivity between BTY and either ZZ-R 127 or LFBK$\alpha_{V} \beta_{6}(p>0.05)$. Nonetheless, the LFBK- $\alpha_{V} \beta_{6}$ cells showed a high degree of diagnostic capability by successfully propagating virus from all epithelium suspensions tested, whereas three viral suspensions were unable to replicate in either the BTY or ZZ-R 127 cells. A/PAK/25/2016 was undetected in BTY cells, despite originally being isolated in this cell type, and A/TUR/8/2015 and $\mathrm{O} / \mathrm{SRL} / 3 / 2017$ were undetected in ZZ-R 127 cells.

Eight O/CATHAY epithelium suspensions were titrated using IB-RS-2, ZZ-R 127, and LFBK- $\alpha_{V} \beta_{6}$ cells. Despite the eight suspensions being originally isolated in IB-RS-2 cells during diagnostic testing at the time of submission, only one epithelium suspension (HKN/5/2016) was able to generate a titer in IB-RS-2 cells during repeat testing in this study. Although the epithelium suspensions had been stored at $-80^{\circ} \mathrm{C}$ since use, it is likely that the viral titer of the samples had decreased during storage and through freeze-thawing. The majority of these samples (6 of 8) did not cause CPE in the ZZ-R 127 cells; only two epithelium suspensions, $\mathrm{HKN} / 11 / 2017$ and $\mathrm{HKN} / 5 / 2016$, generated viral titers. In contrast, all eight samples replicated in LFBK- $\alpha_{V} \beta_{6}$ cells. The LFBK $-\alpha_{V} \beta_{6}$ cells had increased sensitivity to the O/CATHAY topotype in comparison to IB-RS-2, with higher titers observed for all eight epithelium suspensions correlating to a lower limit of detection.

Initially, six porcine epithelium suspensions, negative for virus isolation using BTY and IB-RS-2 cells but positive for FMDV genome, were inoculated onto LFBK- $\alpha_{V} \beta_{6}$ cells. From these six suspensions, two viruses were isolated in $L F B K-\alpha_{V} \beta_{6}$ cells (Table 2). A further 20 porcine epithelium suspensions originating from Hong Kong SAR were inoculated onto BTY, IBRS-2, and LFBK- $\alpha_{V} \beta_{6}$ cells in parallel at the time of submission. Out of these 20 suspensions, 12 viruses were isolated in LFBK$\alpha_{V} \beta_{6}$ cells only. In total, viruses were isolated in 14/26 samples using LFBK- $\alpha_{V} \beta_{6}$ cells, which otherwise would not have been undetected, and were subsequently characterized by antigen ELISA and VP1 sequencing as O/CATHAY topotype.

\section{Effects of Sample Matrices}

No cytotoxicity was observed in the BTY cultures for any of the matrices tested. Cytotoxicity was not observed in IBRS-2, ZZ-R 127, and LFBK- $\alpha_{V} \beta_{6}$ cells for serum, probang fluid and milk; however, whole blood caused cytotoxicity in all four replicates of each of the continuous cell lines 


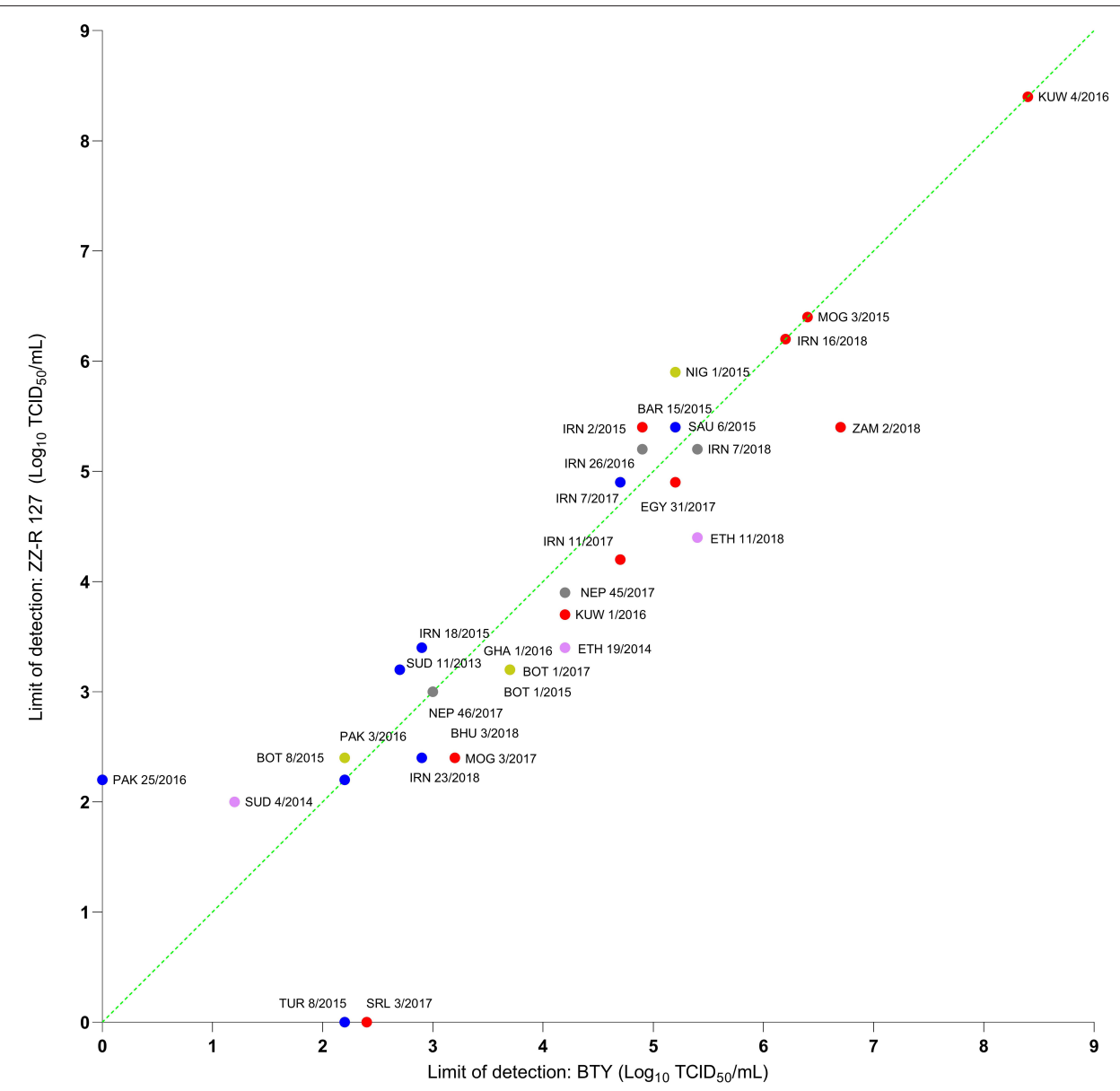

FIGURE 4 | Titers of epithelium suspensions tested on primary BTY cells and ZZ-R 127 cells. Samples are color coded based on FMDV serotype as follows: O, A, SAT 1, SAT 2, and Asia 1. The dotted green line indicates where the limit of detection was identical between the cells; samples with data points above the line indicate a lower limit of detection in ZZ-R 127 and samples with data points below the line indicate a lower limit of detection in BTY cells.

where patches of adherent cells were stripped from the tube surfaces. No cytotoxicity was caused by the $10 \%$ pig fecal suspension, which was inoculated onto IB-RS-2 and LFBK- $\alpha_{V} \beta_{6}$ cells.

\section{Susceptibility to Other Vesicular Viruses}

No CPE was observed in BTY cells $72 \mathrm{~h}$ after inoculation with SVV, VESV, and VSV, indicating BTY cells cannot propagate these viruses (Table 3). The ZZ-R 127 cells were able to propagate VESV and VSV, producing CPE in each of the replicates, whereas SVV was unable to propagate as indicated by the lack of CPE. The IB-RS- 2 and LFBK- $\alpha_{V} \beta_{6}$ cells were able to support the replication of all three vesicular viruses tested.

\section{DISCUSSION}

In this study, we have shown that the ZZ-R 127 and LFBK$\alpha_{V} \beta_{6}$ cell lines were susceptible to FMDV for $>100$ passages (Table 4), and the analytical limit of detection of these cell lines was comparable to primary BTY cell cultures. In comparison, the sensitivity of the IB-RS-2 cell line was significantly lower than ZZ-R 127, LFBK- $\alpha_{V} \beta_{6}$, and BTY cells. Our results highlight the known decreased sensitivity of these cells to FMDV (8). The IB-RS-2 cells lost sensitivity over time, but the ZZ-R 127 and LFBK- $\alpha_{V} \beta_{6}$ cells remained consistently sensitive during progressive sub-culturing (Figures 1, 2). These data confirmed previous studies that reported the ZZ-R 127 and LFBK- $\alpha_{\mathrm{V}} \beta_{6}$ cell lines were highly sensitive to $\operatorname{FMDV}(10,11,21)$.

In comparison to IB-RS-2, our data highlight the increased longetivity of the ZZ-R 127 and LFBK-avb6 cell lines to support FMDV replication. We anticipate that these findings will be broadly transferable to other laboratories, but specific cell batches and culture conditions may influence these results. Therefore, prior to use for routine diagnostics, we recommend that cell sensitivity should be monitored using dilutions of a wellcharacterized reference FMD virus.

When the diagnostic sensitivities of ZZ-R 127 and LFBK- $\alpha_{V} \beta_{6}$ cells were assessed using a range of FMDV field strains, the LFBK$\alpha_{V} \beta_{6}$ cells detected all 32 samples (Table 4) whereas, the ZZ-R 127 and BTY cells detected 30 and 31 samples, respectively. The 


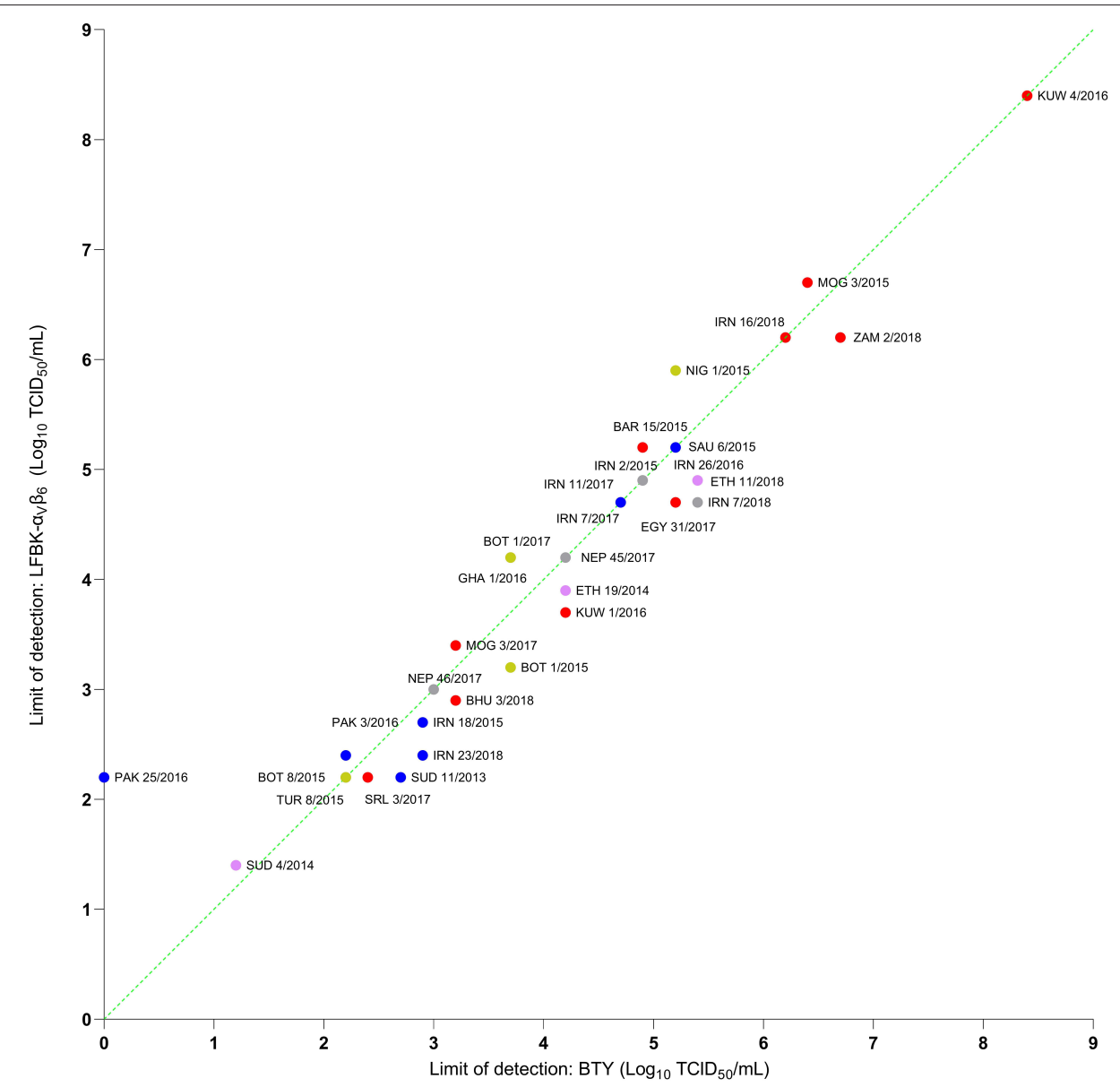

FIGURE 5 | Titers of epithelium suspensions tested on primary BTY cells and LFBK- $\alpha_{v} \beta_{6}$ cells. Samples are color coded based on FMDV serotype as follows: $\mathbf{O}$, A, SAT 1, SAT 2, and Asia 1. The dotted green line indicates where the limit of detection was identical between the cells; samples with data points above the line indicate a lower limit of detection in LFBK- $\alpha_{v} \beta_{6}$ and samples with data points below the line indicate a lower limit of detection in BTY cells.

32 samples were selected to encompass multiple FMDV serotypes and topotypes (serotype O $n=20$, A $n=8$, SAT $1 n=4$, SAT 2 $n=3$, and Asia $1 n=5)$. Serotype $\mathrm{C}$ was not included in this study because it is not known to be circulating; it was last detected in Kenya and Brazil in 2004 (26). No SAT 3 epithelium suspensions were tested due to limited availability of material.

Cell lines of porcine origin are utilized for the detection of pig-adapted FMDV topotypes (e.g., O/CATHAY) and other porcinophilic vesicular viruses. Here, we demonstrated that LFBK- $\alpha_{V} \beta_{6}$ cells were sensitive to SVDV for $>100$ passages, and provided a significantly higher limit of detection than the IB-RS-2 cell line (Figure 3 ). The LFBK- $\alpha_{V} \beta_{6}$ cells were also highly susceptible to infection with isolates from the pig-adapted O/CATHAY FMDV topotype. Overall, our data demonstrated that the LFBK- $\alpha_{V} \beta_{6}$ cell line is more sensitive to FMDV and SVDV than IB-RS-2, possibly because of the constitutive expression of the bovine $\alpha_{V} \beta_{6}$ integrin receptor. The only potential disadvantage of the LFBK- $\alpha_{V} \beta_{6}$ cell line is that they are contaminated with a non-cytopathic BVDV (Rodriguez LL, personal communication, 2019).
The most common sample type submitted to the WRLFMD for the diagnosis of vesicular diseases is epithelium from vesicular lesions. FMD virus can be isolated from other samples types, including whole blood, serum, milk, probang fluid, and feces; however, these matrices can cause detrimental effects to cells, and thus compromise virus isolation. Of the matrices tested, primary BTY cells were the most robust, in that no cytotoxicity was observed. No cytotoxicity was observed in ZZ-R 127 and LFBK- $\alpha_{V} \beta_{6}$ cells after inoculation with serum and probang fluid, supporting the findings that these cell types can be used to isolate FMDV from serum and probang of experimentally infected animals (21). The only matrix that caused cytotoxicity was the undiluted bovine whole blood, which stripped patches of cells from the monolayers of IB-RS-2, ZZ-R 127, and LFBK- $\alpha_{V} \beta_{6}$.

While virus isolation is a sensitive diagnostic test, the observation of CPE is not virus specific. There are several notifiable diseases that are clinically indistinguishable from FMDV, such as VSV, VESV, and SVV, which cause similar CPE in cell culture. Of the four cell types tested, IB-RS- 2 and LFBK- $\alpha_{V} \beta_{6}$ cells were the most versatile, in that VSV, VESV, and SVV were all 
TABLE 2 | Number of CPE positive replicates for BTY, IB-RS-2, and LFBK- $\alpha_{\vee} \beta_{6}$ post-inoculation with porcine samples received from Hong Kong $(n=26)$.

\begin{tabular}{|c|c|c|c|c|}
\hline Sample reference & BTY & IB-RS-2 & LFBK- $\alpha_{V} \beta_{6}$ & FMDV $3 D \mathbf{C}_{\mathrm{T}}$ values \\
\hline HKN 5/2017* & $0 / 5$ & $0 / 5$ & $1 / 4$ & 28.68 \\
\hline HKN 2/2018* & $0 / 5$ & $0 / 5$ & $0 / 5$ & 25.57 \\
\hline HKN 3/2018* & $0 / 5$ & $0 / 5$ & $0 / 5$ & 20.22 \\
\hline HKN 4/2018* & $0 / 5$ & $0 / 5$ & $2 / 5$ & 25.72 \\
\hline HKN 7/2018* & $0 / 5$ & $0 / 5$ & $0 / 5$ & 32.91 \\
\hline HKN 9/2018* & $0 / 5$ & $0 / 5$ & $0 / 5$ & 28.30 \\
\hline HKN 10/2018 & $0 / 5$ & $0 / 5$ & $0 / 5$ & 27.91 \\
\hline HKN 11/2018 & $0 / 5$ & $0 / 5$ & $5 / 5$ & 21.53 \\
\hline HKN 12/2018 & $0 / 5$ & $0 / 5$ & $3 / 5$ & 38.37 \\
\hline HKN 13/2018 & $0 / 5$ & $5 / 5$ & $5 / 5$ & 24.94 \\
\hline HKN 14/2018 & $0 / 5$ & $0 / 5$ & $5 / 5$ & $\mathrm{No} \mathrm{C}_{T}$ \\
\hline HKN 15/2018 & $0 / 5$ & $0 / 5$ & $5 / 5$ & 33.94 \\
\hline HKN 16/2018 & $0 / 5$ & $0 / 5$ & $5 / 5$ & 34.51 \\
\hline HKN 17/2018 & $0 / 5$ & $0 / 5$ & $4 / 5$ & 39.08 \\
\hline HKN 18/2018 & $0 / 5$ & $0 / 5$ & $3 / 5$ & 32.92 \\
\hline HKN 19/2018 & $0 / 5$ & $0 / 5$ & $0 / 5$ & 35.89 \\
\hline HKN 20/2018 & $0 / 5$ & $5 / 5$ & $5 / 5$ & 18.83 \\
\hline HKN 21/2018 & $0 / 5$ & $1 / 5$ & $5 / 5$ & 34.43 \\
\hline HKN 22/2018 & $0 / 5$ & $0 / 5$ & $0 / 5$ & $36.35^{\dagger}$ \\
\hline HKN 23/2018 & $0 / 5$ & $5 / 5$ & $5 / 5$ & 22.71 \\
\hline HKN 1/2019 & $0 / 5$ & $2 / 5$ & $4 / 4$ & 33.05 \\
\hline HKN 2/2019 & $0 / 5$ & $0 / 5$ & $4 / 4$ & 35.99 \\
\hline HKN 4/2019 & $0 / 5$ & $0 / 5$ & $4 / 4$ & 33.02 \\
\hline HKN 5/2019 & $0 / 5$ & $0 / 5$ & $4 / 4$ & $\mathrm{No} \mathrm{C}_{T}$ \\
\hline HKN 6/2019 & $0 / 5$ & $0 / 5$ & $3 / 4$ & 34.76 \\
\hline HKN 7/2019 & $0 / 5$ & $0 / 5$ & $4 / 4$ & $36.36^{\dagger}$ \\
\hline
\end{tabular}

Samples were received to the WRLFMD between 2017 and 2019. All isolated viruses were confirmed as O/CATHAY topotype by VP1 sequencing. FMDV 3D qRT-PCR $C_{T}$ values are included for comparison and are an average of two replicates.

${ }^{*} L F B K-\alpha v \beta_{6}$ inoculated independently from BTY and IB-RS-2 cells.

${ }^{\dagger}$ Sample provided a $C_{T}$ value in only one replicate.

TABLE 3 | Number of replicates per cell line with CPE after inoculation with SW, VESV, and VSV.

\begin{tabular}{lcccc}
\hline Cell line & BTY & ZZ-R 127 & LFBK- $\boldsymbol{\alpha}_{V} \boldsymbol{\beta}_{\mathbf{6}}$ & IB-RS-2 \\
\hline SW-MN-88-36695 & $0 / 3$ & $0 / 3$ & $3 / 3$ & $3 / 3$ \\
VESV-K54 & $0 / 3$ & $3 / 3$ & $3 / 3$ & $3 / 3$ \\
VSV-New Jersey & $0 / 3$ & $3 / 3$ & $3 / 3$ & $3 / 3$ \\
\hline
\end{tabular}

able to replicate, confirming previous results that the LFBK- $\alpha_{V} \beta_{6}$ cells are capable of propagating VESV and VSV (11). Cell lines currently available for the isolation of SVV include swine testis cells, porcine kidney, IB-RS-2 and BHK (27). To our knowledge, this is the first time LFBK- $\alpha_{V} \beta_{6}$ cells have been identified as a resource for the isolation of SVV.

As mentioned, primary BTY cells are accepted as the most sensitive cell culture for the isolation of FMDV, but their preparation is expensive and labor intensive (23). Hence, diagnostic laboratories would benefit from a continuous cell line with the same sensitivity as primary BTY cells. Although sensitivity comparisons have been performed between BTY and ZZ-R 127 (10) and between ZZ-R 127 and LFBK$\alpha_{V} \beta_{6}$ cells (21), this is the first study to compare LFBK$\alpha_{V} \beta_{6}$ and primary BTY cells. The results indicate that both ZZ-R 127 and LFBK- $\alpha_{V} \beta_{6}$ cell lines are suitable alternatives to BTY cells for the isolation of FMDV. Furthermore, the LFBK $-\alpha_{V} \beta_{6}$ cells have multiple advantages in that the cells grow quickly in cell culture, remained stable for $>100$ passages, and were able to support growth of all the other vesicular viruses tested. This contrasts with the ZZ-R 127 cells which grow slowly and were not able to support growth of SVV.

Rapid and accurate diagnosis underpins the control of FMDV. Although virus isolation is not a rapid diagnostic test (i.e., it can take 1-6 days to isolate a virus), it is necessary for downstream testing, such as vaccine matching. At WRLFMD, FMD serotype is most commonly determined using a polyclonal antigen ELISA (5), or a monoclonal antigen ELISA (28). Epithelium suspensions prepared from clinical samples can be tested directly on an ELISA, but only approximately a third of samples submitted to the WRLFMD contain the concentration of viral antigen needed for detection [e.g., minimum concentration of $1-2 \mathrm{ng} / \mathrm{mL}$ of virus antigen for detection with the polyclonal antigen ELISA (29)]. In addition, samples such as blood, serum, probang fluid, milk, and feces cannot be tested directly on ELISA. Consequently, clinical samples such as these must be isolated in cell culture before testing with a serotyping antigen ELISA.

Recently, lineage-specific real-time RT-PCR assays have been developed to circumvent the need for virus isolation and the handling of "live" virus (30-33). However, due to the diversity of FMDV topotypes and the rapid mutation rate of the RNA genome (34), these assays need to be tailored to geographic regions and require ongoing monitoring of sensitivity. Additionally, these assays are "dead end tests," as the material produced cannot be used for downstream testing, such as vaccine matching. Although serotyping real-time RT-PCRs have advantages, these assays cannot yet replace virus isolation.

Currently, the use of sensitive cell cultures are required for testing vaccine efficacy to a particular field strain (25). The virus neutralization test requires the serial passage of an FMDV isolate to generate a high viral titer and is dependent on the use of continuous cell lines, such as BHK and IB-RS-2, to determine the ability of antibodies to neutralize "live" virus. While both ZZ-R 127 and LFBK- $\alpha_{V} \beta_{6}$ cell lines represent suitable alternatives, it is expected that the LFBK- $\alpha_{V} \beta_{6}$ cell line will undergo validation for virus neutralization tests in the WRLFMD due to their susceptibility to a wider range of FMDV strains, including the O/CATHAY topotype.

\section{CONCLUSIONS}

In this study, the FMDV sensitivity of the ZZ-R 127 and LFBK- $\alpha_{V} \beta_{6}$ cell lines were comparable to primary BTY cells, and significantly higher than the IB-RS-2 cell line (Table 4). In 
TABLE 4 | Summary comparing the results among BTY, ZZ-R 127, LFBK- $\alpha_{\vee} \beta_{6}$, and IB-RS-2.

\begin{tabular}{|c|c|c|c|c|c|}
\hline & & \multicolumn{4}{|c|}{ Cell type } \\
\hline & & BTY & ZZ-R 127 & LFBK- $\alpha \vee \beta_{6}$ & IB-RS-2 \\
\hline \multicolumn{2}{|c|}{ Duration of SVDV sensitivity } & ND & ND & $>100$ passages & $>100$ passages \\
\hline Sensitivity of cell lines & FMD/A/IRN/24/2012 & 5.8 & 5.7 & 5.8 & 4.3 \\
\hline (Avg. $\log _{10} T C I D_{50} / \mathrm{mL}$ ) & SVD/UKG/77/80 & ND & ND & 5.2 & 4.5 \\
\hline \multicolumn{2}{|c|}{ Detected FMDV epithelium suspensions } & $31 / 32$ & $30 / 32$ & $32 / 32$ & ND \\
\hline \multicolumn{2}{|c|}{ Detected O/CATHAY epithelium suspensions } & ND & $2 / 8$ & $8 / 8$ & $1 / 8$ \\
\hline \multicolumn{2}{|c|}{ Detected O/CATHAY diagnostic submissions } & $0 / 26$ & ND & $19 / 26$ & $5 / 26$ \\
\hline \multicolumn{2}{|c|}{ Susceptibility to other vesicular viruses } & None & VESV, VSV & VESV, VSV, SVV & VESV, VSV, SW \\
\hline
\end{tabular}

ND, not done.

addition, the LFBK $-\alpha_{V} \beta_{6}$ cells were significantly more sensitive to SVDV than the IB-RS-2 cells and exhibited a high diagnostic capability for detecting the O/CATHAY pig-adapted FMDV strain. Overall, ZZ-R 127 and LFBK- $\alpha_{V} \beta_{6}$ cell lines have been confirmed as sensitive tools for FMDV diagnostic testing. The LFBK- $\alpha_{V} \beta_{6}$ cells outperformed the IB-RS-2 throughout testing and therefore, have been identified as a highly sensitive porcine cell line for the routine detection of FMDV strains and porcinophilic vesicular viruses.

\section{DATA AVAILABILITY STATEMENT}

The raw data supporting the conclusions of this article will be made available by the authors, without undue reservation.

\section{AUTHOR CONTRIBUTIONS}

AG, VM, BW, and DK conceived the study. DK obtained funding. AG, VM, BW, MA, and $\mathrm{EH}$ performed virus titrations

\section{REFERENCES}

1. Knight-Jones TJD, Rushton J. The economic impacts of foot and mouth disease - what are they, how big are they and where do they occur? Prev Vet Med. (2013) 112:161-73. doi: 10.1016/j.prevetmed.2013.07.013

2. Belsham GJ, Kristensen T, Jackson T. Foot-and-mouth disease virus : prospects for using knowledge of virus biology to improve control of this continuing global threat. Virus Res. (2020) 281:197909. doi: $10.1016 /$ j.virusres.2020.197909

3. OIE. Foot and mouth disease (infection with foot and mouth disease virus). In: Manual of Diagnostic Tests and Vaccines for Terrestrial Animals. Paris: World organisation for Animal Health (OIE) (2017). p. 433-64.

4. Knowles NJ, Samuel A. Molecular epidemiology of foot-and-mouth disease virus. Virus Res. (2003) 91:65-80. doi: 10.1016/S0168-1702(02)00260-5

5. Ferris NP, Dawson M. Routine application of enzyme-linked immunosorbent assay in comparison with complement fixation for the diagnosis of foot-and-mouth and swine vesicular diseases. Vet Microbiol. (1988) 16:201-9. doi: 10.1016/0378-1135(88)9 0024-7 and inoculations. AG performed data interpretation and wrote the manuscript. All authors read and approved the manuscript content.

\section{FUNDING}

This research was supported by funding from the United Kingdom Department for Environment, Food and Rural Affairs (DEFRA; projects SE1128 and SE1129). The Pirbright Institute receives strategic support from the Biotechnology and Biological Research Council (BBSRC), United Kingdom (projects BBS/E/I/0007035, BBS/E/I/00007036, and BBS/E/I/00007037).

\section{ACKNOWLEDGMENTS}

The authors thank international partners for submitting the samples included in this study and would like to acknowledge Drs L. Rodriguez and M. LaRocco (Plum Island, USDA/ARS) for providing the LFBK- $\alpha_{V} \beta_{6}$ cell line. 
12. LaRocco M, Krug PW, Kramer E, Ahmed Z, Pacheco JM, Duque $\mathrm{H}$, et al. Correction for LaRocco et al., A continuous bovine kidney cell line constitutively expressing bovine $\alpha \mathrm{v} \beta 6$ integrin has increased susceptibility to foot-and-mouth disease virus. J Clin Microbiol. (2015) 53:755. doi: 10.1128/JCM.03220-14

13. Fukai K, Onozato H, Kitano R, Yamazoe R, Morioka K, Yamada M, et al. Availability of a fetal goat tongue cell line ZZ-R 127 for isolation of Foot-andmouth disease virus (FMDV) from clinical samples collected from animals experimentally infected with FMDV. J Vet Diagn Invest. (2013) 25:770-4. doi: 10.1177/1040638713508400

14. Wungak YS, Olugasa BO, Ishola O, Lazarus D, Chukwuedo AA, Ularamu HG. Isolation and serotyping of foot-and-mouth disease virus in cattle collected from North Central, Nigeria. Nig Vet J. (2019) 40:178. doi: 10.4314/nvj.v40i3.1

15. Orton RJ, Wright CF, King DP, Haydon DT. Estimating viral bottleneck sizes for FMDV transmission within and between hosts and implications for the rate of viral evolution. Interface Focus. (2020) 10:20190066. doi: 10.1098/rsfs.2019.0066

16. Zhang F, Perez-Martin E, Juleff N, Charleston B, Seago J. A replicationcompetent foot-and-mouth disease virus expressing a luciferase reporter. $J$ Virol Methods. (2017) 247:38-44. doi: 10.1016/j.jviromet.2017.05.011

17. Ludi A, Ahmed Z, Pomeroy LW, Pauszek SJ, Smoliga GR, Moritz M, et al. Serotype diversity of foot-and-mouth-disease virus in livestock without history of vaccination in the far North Region of cameroon. Transbound Emerg Dis. (2016) 63:e27-38. doi: 10.1111/tbed.12227

18. Nishi T, Yamada M, Fukai K, Shimada N, Morioka K, Yoshida K, et al. Genome variability of foot-and-mouth disease virus during the short period of the 2010 epidemic in Japan. Vet Microbiol. (2017) 199:62-7. doi: 10.1016/j.vetmic.2016.12.025

19. Wijnker JJ, Haas B, Berends BR. Inactivation of foot-and-mouth disease virus in various bovine tissues used for the production of natural sausage casings. Int J Food Microbiol. (2012) 153:237-40. doi: 10.1016/j.ijfoodmicro.2011.11.013

20. Bhatt M, Mohapatra JK, Pandey LK, Mohanty NN, Das B, Prusty BR, et al. Mutational analysis of foot and mouth disease virus nonstructural polyprotein 3AB-coding region to design a negative marker virus. Virus Res. (2018) 243:36-43. doi: 10.1016/j.virusres.2017.10.010

21. Fukai K, Morioka K, Yamada M, Nishi T, Yoshida K, Kitano R, et al. Comparative performance of fetal goat tongue cell line ZZR 127 and fetal porcine kidney cell line LFBK- $\alpha \mathrm{v} \beta 6$ for foot-andmouth disease virus isolation. J Vet Diagn Invest. (2015) 27:516-21. doi: $10.1177 / 1040638715584156$

22. EuFM D. Minimum Biorisk Management Standards for Laboratories Working with Foot-and-Mouth Disease Virus. Rome: 40th General Session of the European Commission for the Control of Foot-and-Mouth Disease) (2013).

23. Snowdon WA. Growth of foot-and-mouth disease virus in monolayer cultures of calf thyroid cells. Nature. (1966) 210:1079-80. doi: 10.1038/2101 $079 \mathrm{a} 0$

24. King DP, Burman A, Gold S, Shaw AE, Jackson T, Ferris NP. Integrin sub-unit expression in cell cultures used for the diagnosis of footand-mouth disease. Vet Immunol Immunop. (2011) 140:259-65. doi: $10.1016 /$ j.vetimm.2011.01.008s
25. OIE. Foot-and-mouth disease virus. In: Manual of Diagnostic Tests and Vaccines for Terrestrial Animal. Paris: World organisation for Animal Health (OIE) (2018). p. 433-64.

26. King DP, Nardo AD, Henstock M. OIE/FAO Foot-and-Mouth Disease Reference Laboratory Network Annual Report 2017. (2017) Available Online at: https://www.foot-and-mouth.org/sites/foot/files/user-files/researchpaper/pdf/09-18/NetworkReport 2017.pdf (accessed December 12, 2019).

27. Zhang X, Zhu Z, Yang F, Cao W, Tian H, Zhang K, et al. Review of seneca valley virus: a call for increased surveillance and research. Front Microbiol. (2018) 9:940. doi: 10.3389/fmicb.2018.00940

28. Ferris NP, Abrescia NGA, Stuart DI, Jackson T, Burman A, King DP, et al. Utility of recombinant integrin Av $\beta 6$ as a capture reagent in immunoassays for the diagnosis of foot-and-mouth disease. J Virol Methods. (2005) 127:69-79. doi: 10.1016/j.jviromet.2005.02.014

29. Shaw AE, Reid SM, King DP, Hutchings GH, Ferris NP. Enhanced laboratory diagnosis of foot and mouth disease by real-time polymerase chain reaction. Rev Sci Tech OIE. (2004) 23:1003-9. doi: 10.20506/rst.23.3.1544

30. Bachanek-Bankowska K, Mero HR, Wadsworth J, Mioulet V, Sallu R, Belsham GJ, et al. Development and evaluation of tailored specific real-time RT-PCR assays for detection of foot-and-mouth disease virus serotypes circulating in East Africa. J Virol Methods. (2016) 237:114-20. doi: 10.1016/j.jviromet.2016.08.002

31. Jamal SM, Belsham GJ. Development and characterization of probe-based real time quantitative rt-pcr assays for detection and serotyping of footand-mouth disease viruses circulating in West Eurasia. PLoS ONE. (2015) 10:e0135559. doi: 10.1371/journal.pone.0135559

32. Reid SM, Mioulet V, Knowles NJ, Shirazi N, Belsham GJ, King DP. Development of tailored real-time RT-PCR assays for the detection and differentiation of Serotype O, A and Asia-1 foot-and-mouth disease virus lineages circulating in the Middle East. J Virol Methods. (2014) 207:146-53. doi: 10.1016/j.jviromet.2014.07.002

33. Ahmed HA, Salem SAH, Habashi AR, Arafa AA, Aggour MGA, Salem GH, et al. Emergence of foot-and-mouth disease virus SAT 2 in Egypt during 2012. Transbound Emerg Dis. (2012) 59:476-81. doi: 10.1111/tbed.12015

34. Domingo E, Baranowski E, Ruiz-Jarabo CM, Martín-Hernández AM, Sáiz JC, Escarmís C. Quasispecies structure and persistence of RNA viruses. Emerging Infect Dis. (1998) 4:521-7. doi: 10.3201/eid0404.980402

Conflict of Interest: The authors declare that the research was conducted in the absence of any commercial or financial relationships that could be construed as a potential conflict of interest.

The handling editor declared a past co-authorship with one of the author DK.

Copyright (c) 2020 Gray, Wood, Henry, Azhar, King and Mioulet. This is an openaccess article distributed under the terms of the Creative Commons Attribution License (CC BY). The use, distribution or reproduction in other forums is permitted, provided the original author(s) and the copyright owner(s) are credited and that the original publication in this journal is cited, in accordance with accepted academic practice. No use, distribution or reproduction is permitted which does not comply with these terms. 